\title{
Cancer Screening: Global Debates and Cuban Experience
}

\section{Rebeca S. González MD MS}

\begin{abstract}
A review was conducted of screening strategies for detecting the main cancer sites for which screening has been recommended, assessing $\mathrm{WHO}$ and other international organizations' positions, as well as the requirements of Cuba's cancer control strategy. Universally, screening is recommended for cervical, breast and colorectal cancer, all included in the Cuban strategy. Additionally, in Cuba, PSA testing is indicated for men considered at risk (aged $>45$ years with family history) and those aged $>50$ years who request it; annual oral exams and teaching of oral selfexamination are recommended for the entire population; and for adults aged $>35$ years, active annual oral cancer case finding. Screening for skin cancer is performed by physical examination of individuals at risk. To maximize benefits of early cancer detection, greater coverage is needed as well as studies of how well screening is performing under current Cuban conditions.
\end{abstract}

KEYWORDS Cancer, early detection, screening, secondary prevention, breast cancer, cervical cancer, colorectal cancer, skin cancer, oral cancer, Cuba

\section{INTRODUCTION}

A national cancer control program is a public health program designed to reduce cancer incidence and mortality and improve cancer patients' quality of life, through systematic and equitable implementation of evidence-based strategies for prevention, early detection, treatment and palliative care, making the best possible use of available resources.[1]

Early detection is based on diagnosis early in a cancer's development, in pre-symptomatic stages, when treatment is more likely to be effective. Early detection depends on two main components: education and screening.[1] An estimated $30 \%$ of cancers could be cured with early detection and appropriate treatment.[2]

Screening is the presumptive identification of unrecognized disease by means of tests that can be applied rapidly to separate the healthy from the possibly sick.[3] While appropriateness of some specific tests is still debated, cancer screening as such is accepted by the international medical community based on the evidence.

Screening program success depends on various factors related to the disease, the proposed test and the health system. The cancers chosen for screening should be common and associated with high morbidity and mortality, and there should be treatment available that can reduce these indicators. The screening test should be acceptable to the population for which it is designed, sufficiently sensitive to detect early lesions, feasible for use in medical practice, and relatively inexpensive.[1] It should be sensitive enough to detect cancer in those who have the disease and specific enough to correctly rule out individuals without the disease. Two other important test characteristics depend on sensitivity and specificity, but also on disease prevalence in the population screened: positive predictive value, or extent to which those who test positive actually have the disease; and negative predictive value, or extent to which those who test negative are actually disease free.[1]
Characteristics of national health systems also influence which screening approaches are appropriate. The system must have the resources to deliver screening to a sufficiently large proportion of the population to obtain the expected benefits, and it must also have the capacity to provide subsequent diagnosis, treatment and followup. In developing such screening strategies, WHO recommends that national cancer control programs should not impose the advanced technologies of high-income countries on countries with more limited resources. Hence, policies will undoubtedly differ among countries.[1]

Early detection is a strategic component of Cuba's Comprehensive Cancer Control Program. This in turn comprises three different approaches: population screening (of apparently healthy people), targeted screening (of individuals at risk) and case finding in symptomatic patients. The Program is considering organizing pilot areas to validate study findings in asymptomatic populations, to assess generalizability of screening trial results.[4]

In each of Cuba's 168 municipalities, a Center for Comprehensive Active Screening has been set up, reporting to the municipal health department. These are laboratories outfitted with ultramicroanalytic system (SUMA, the Spanish acronym) technology, staffed by personnel trained in its use. Havana's Immunoassay Center supports laboratory operations through reagent distribution, technical assistance with equipment repair and maintenance, and analytical assistance as requested by clients or in response to results of external audits. The laboratories were conceived to expand diagnostic capabilities beyond traditional techniques and to conduct other activities for program development and quality assurance, as well as to enable early detection of cancers included in screening programs, to conduct screening studies on population groups according to risk stratification and population health status, and to ensure comprehensive services for improved diagnostic quality and health outcomes.

This paper reviews screening strategies for the main cancer sites for which screening is recommended and assesses the criteria and results of studies by WHO and other international organizations and institutions, as well as the recommendations of Cuba's cancer control strategy.

Cervical cancer The purpose of cervical cancer screening is to detect precancerous lesions as well as in situ or very early invasive cancer, when treatment is most effective. Three different types of tests are available: conventional (Pap) and liquid-media cytology, visual inspection with acetic acid, and HPV testing for oncogenic HPV types. Screening with appropriate followup can attain significant reductions in incidence and mortality from advanced cervical cancer.[2] One risk of such screening is that detection of low-grade squamous intraepithelial lesions in young women may lead to followup tests and possibly unnecessary treatment. There is also the chance of false positive results, causing anxiety, and of false negative results that can delay medical treatment.[5]

The US National Cancer Institute $(\mathrm{NCI})$ and the US Preventive Services Task Force (USPSTF) recommend that women aged 
$\geq 21$ have a Papanicolau cytology (Pap) test every 3 years; in women aged 30-65 years, frequency may be reduced to every 5 years if combined with HPV testing.[6] These recommendations coincide with those of the American Cancer Society in association with the American Society for Colposcopy and Cervical Pathology and the American Society for Clinical Pathology.[7] WHO recommends, as a minimum, one-time screening for all women aged 30-49. WHO also recommends that screening intervals should be at least five years, or at least ten years in the case of HPV testing.[8]

Since 1968, Cuba's Ministry of Public Health (MINSAP, the Spanish acronym), in coordination with civil-society organizations, has implemented cervical cancer control activities. The current strategy, applied in primary health care, is Pap testing every three years for women aged 25-64 years. If results are abnormal, the woman is referred to one of 45 secondary-level cervical pathology clinics that provide coverage across Cuba, equipped with the personnel and technologies needed for diagnosis, treatment and followup. [9] Each clinic has a SUMASCOPE videocolposcope and SUMACRAF electrocautery equipment coupled with an ASPIRAL smoke aspirator, all manufactured by Havana's Immunoassay Center and distributed by TecnoSuma International.

These same videocolposcopes have been installed in 98 municipal clinics for benign cervical pathology, reinforcing this strategy; all 168 municipalities in Cuba are expected to be equipped by 2015. Sets of instruments and disposable reagents are also being distributed to increase program coverage; all components are manufactured in Cuba, reducing costs.

Since 1997, Pap tests are repeated every three years for the age group indicated. From 1997 to 1999, 2,074,806 women aged $>25$ years were tested, for an estimated coverage of $66.3 \%$. From 2009 to 2011 , the number increased slightly to $2,104,567$, for an estimated coverage of $67 \%$.[10] The proportion of cases diagnosed at clinical stage 1 rose from $12.2 \%$ in 2011 to $18.4 \%$ in 2012 , while the proportion diagnosed at stage 2 rose from $5.7 \%$ to $9.2 \%$. That same year, cancer became the leading cause of death in Cuba, but cervical cancer mortality fell, from 8.3 per 100,000 women (466 deaths) in 2011 to 7.9 per 100,000 (442 deaths) in 2012.[10]

However, the decrease in cervical cancer mortality (the fifth leading cause of cancer deaths in Cuban women) is less than hoped for. Indeed, $67 \%$ is below the coverage threshold for screening to produce palpable benefits.[2] This begs review of how the strategy is being applied, as well as of related organizational factors in the system that may be preventing attainment of screening's full benefit.

Breast cancer The purpose of breast cancer screening is early detection. With appropriate facilities, screening by mammography, with or without physical breast examination, plus followup of individuals with positive or suspicious findings, can reduce breast cancer mortality by up to one third.[1] Such screening also has risks. It can lead to diagnosis of cancers that never would have caused symptoms or death and in so doing, expose patients to treatment risks and side effects. In addition, false positive results sometimes occur, engendering further diagnostic testing and creating anxiety. On the other hand, false negative results can delay diagnosis and treatment. Radiation itself also increases breast cancer risk.[11]
$\mathrm{NCl}$ and USPSTF recommend breast cancer screening with mammography every two years for women aged 50-74 years. They do not recommend either mammography or self-examination screening for women aged 40-49 years, noting that risks outweigh expected benefits in this age group.[12] WHO recommends mammography screening for women aged 50-64 years who visit health institutions.[1,2] Unfortunately, mammography is expensive, so it is not a viable option for many countries, where priority is use for individual case diagnosis, particularly for women who detect an abnormality during self-examination. $[1,3]$

In Cuba, monthly breast self-examination and an annual checkup by family doctors are recommended for women aged $\geq 30$ years. If findings are suspicious, patients are referred to municipal breast health clinics. If suspicions persist, referrals are made to hospital-based multidisciplinary diagnosis and treatment clinics. Furthermore, a mammogram every two years is recommended for women aged 50-64 years and suspected cases are referred directly to multidisciplinary clinics for diagnosis and hospital treatment (unpublished MINSAP document).[4]

Contrary to international recommendations, Cuba's breast cancer prevention strategy also targets women aged $<50$ years, because the epidemiology of breast cancer in Cuba demands it. In 2009, $26.5 \%$ breast cancer diagnoses $(816 / 3078)$ were in women aged $<50$ years. In 2012, there were 482 breast cancer deaths in women aged <60 years: 32 in women aged $20-39$ years and 450 in women aged $40-59$ years.[10]

In $2013,72,129$ women aged $>30$ years were assessed in municipal breast health clinics and 35,398 in multidisciplinary clinics for diagnosis and hospital treatment. A total of 64,144 mammograms were performed, of which 25,420 were to screen women aged 50-64 years, only 2.6\% coverage (data from Form 241-434-03, National Breast Cancer Control Program 2013, Statistical Information System, MINSAP). Much better program coverage is needed, since screening does not yet appear to impact reduction of breast cancer mortality, which continues to climb. In 2000, there were 1012 breast cancer deaths (18.2/100,000 women); in 2011, there were $1390(24.8 / 100,000)$ and 2012, $1521(27.1 / 100,000)$. [10] Although these rates are not age adjusted, they reflect a real and substantial increase in disease burden.

Colorectal cancer Screening for colorectal cancer is based on detecting adenoma, a specific preneoplastic lesion that can be treated effectively. More than $90 \%$ of colorectal cancer cases are preceded by these premalignant changes. Lifetime risk of colorectal adenoma is $20 \%$, with peak incidence at ages 55-65 years. Lifetime probability of colorectal cancer is $4 \%-6 \%$, with maximum incidence at ages $65-75$ years; it affects men and women equally. Some $75 \%$ of individuals who develop colorectal cancer have no personal or family history of the disease, so risk-group screening is not done, since it would detect only about $20 \%$ of cases. Early detection can lead to cure in $80 \%-$ $90 \%$ of cases.[13]

The tests most recommended for early detection of colorectal cancer are the fecal occult blood test, sigmoidoscopy and colonoscopy. Double-contrast barium enema is another imaging procedure that has been recommended for screening. Other techniques, such as computerized tomographic colonoscopy or virtual colonoscopy, have also been applied but have not yet been shown 
to reduce mortality rates. Trials are under way to assess tests for human DNA in fecal matter or blood samples.[14-16]

Colorectal cancer screening does have potential negative effects. Sigmoidoscopy and colonoscopy can be uncomfortable, even painful. They can also, albeit infrequently, cause complications such as perforation, hemorrhaging or cardiovascular events. Fecal occult blood testing can produce false positives that can lead to further testing - with attendant iatrogenic risks-or false negatives (if the lesion bleeds only intermittently, or not at all), which can delay diagnosis.[17]

In 2007, the World Gastroenterology Organization published the International Digestive Cancer Alliance Practice Guidelines, based on review of the various screening options. The Guidelines involve a screening cascade, with recommendations for settings at six different resource levels, from minimum to high.[13] $\mathrm{NCl}$ and USPSTF recommend three options for screening individuals aged $\geq 50$ years for colorectal cancer: annual fecal occult blood test, sigmoidoscopy every 5 years with fecal occult blood test every 3 years, or colonoscopy every 10 years.[18] WHO recognizes that screening with sigmoidoscopy and annual fecal occult blood testing reduces mortality from colorectal cancer and emphasizes the need for higher population coverage to obtain greater benefits in proportion to costs generated.[1,2]

In Cuba, it is recommended that asymptomatic patients aged $\geq 50$ years have an annual fecal occult blood test and flexible rectosigmoidoscopy or double-contrast barium enema every 5 years. Patients with a family history of colorectal cancer should have a colonoscopy every five years. Since 2013, in addition to the traditional guaiac test for fecal occult blood, a rapid qualitative immunological test to detect occult human blood in fecal matter has been available. Called SUMASOHF, it was designed by the Immunoassay Center and is distributed throughout Cuba by TecnoSuma International. It is a highly sensitive sandwich-type chromatographic immunoassay for early diagnosis and followup of gastrointestinal disorders that provoke bleeding. In 5 minutes, human hemoglobin levels as low as $0.2 \mu \mathrm{g} / \mathrm{mL}$ can be detected in fecal matter.[19] In 2013, SUMASOHF was introduced in the 116 Cuban municipalities with the highest colorectal cancer mortality rates. A total of 50,756 individuals aged $>50$ were screened, coverage of only $2.7 \%$; positivity was $10.4 \%$ (data from Form 241 509-01 SUMA Technology 2013, Statistical Information System, MINSAP). Screening coverage must be increased as quickly as possible to reduce mortality from colorectal cancer, the third leading cause of cancer deaths in Cuba, with 2089 deaths in 2012 (18.6 deaths per 100,000 population).[10]

Prostate cancer Expert opinion on the PSA test has varied over the years. Until recently, many physicians and organizations recommended that men be tested annually beginning at age 50; and men at higher risk even earlier, at 40 or 45 years. Several randomized trials of PSA screening have been conducted, with contradictory results. A study by US $\mathrm{NCl}$ concluded that incidence was rising but mortality was not falling, while the European Randomized Study of Screening for Prostate Cancer (ERSPC) did find a drop in mortality (a trend that seems to be supported by sustained lower rates over a longer period of followup).[20-22]

The majority of urological associations have concluded that generalized population screening with PSA is not appropriate and early detection should be offered only to individuals well informed of the risk of detecting some prostate cancers that would never have inflicted health problems and that could lead to overtreatment. Despite this, many insurance systems cover PSA testing, including Medicare in the United States.[23] The issue remains controversial. In March 2014, the US National Comprehensive Cancer Network (NCCN) published updated guidelines for use of PSA testing in prostate cancer screening, recommending routine screening of men aged $\geq 45$ years, with frequency of subsequent screening dependent on results of baseline screening with PSA and digital rectal examination.[24]

WHO's position is that digital rectal examination is not sufficiently sensitive to detect early stages of the disease, and it is not yet clear whether PSA reduces mortality. WHO insists on the need to establish PSA's effectiveness with well-designed randomized trials, currently under way. $[1,3]$

In Cuba, PSA is recommended for symptomatic patients; men aged $\geq 45$ years with a family history of prostate cancer; and those aged $>50$ years who request it.[4] The test used is UMELISA PSA, an assay designed by the Immunoassay Center to quantify total and free PSA in human serum samples.[25]

Prostate cancer is the second leading cause of cancer deaths in Cuban men, and crude mortality rates have risen in recent years, from 1844 deaths (33.1 per 100,000 men) in 2000 to 2703 deaths (48 per 100,000) in 2012.[10] In 2013, 238,799 PSA tests were performed in the national health system, in $14.5 \%$ of the male population aged $>50$ years, with $14.8 \%$ positivity (data from Form 241-509-01, SUMA Technology 2013, Statistical Information System, MINSAP). Research is needed to assess the results of PSA testing in Cuba's health system. An as-yet unpublished study in the province of Santiago de Cuba is under way, but focusing on PSA screening's impact on incidence, not on mortality.

Oral cancer According to NCI and USPSTF, it has still not been demonstrated that oral cancer screening by direct visual examination reduces mortality from the disease.[26] The Cochrane Oral Health Group concludes that there is insufficient evidence to determine whether screening by visual inspection reduces mortality rates, and there have been no trials of other screening methods. However, there is some evidence that screening may help reduce mortality in patients who use tobacco and alcohol, although the only study included that showed benefits may have been affected by bias due to faulty randomization. [27] WHO agrees that detection of precancerous lesions or early-stage tumors has not yet been shown to reduce oral cancer mortality. $[1,2]$

Cuba's strategy recommends an annual mouth-and-throat exam and teaching oral self-examination for the entire population, and active annual case finding in the community to seek individuals aged $\geq 35$ years at risk, who are then referred for examination. [4] Control actions for this cancer have been carried out in Cuba since 1982, as part of a national oral cancer detection strategy. [28] Data have not been published that could help assess extent and results of the strategy's implementation.

In 2012, cancer of the lip, oral cavity and pharynx was the ninth leading cause of cancer mortality in Cuba in both sexes, with 641 deaths $(5.7 / 100,000$ population), up from 492 in 2009 
(4.4/100,000).[10] Again, these are crude rates and apparent trends may be affected by demographic changes.

Skin cancer $\mathrm{NCl}$, USPSTF and WHO do not consider that there is sufficient evidence that visual inspection (skin check) of asymptomatic individuals leads to reduced skin cancer mortality. $[1,2,29]$

In Cuba, screening by physical examination is recommended for individuals at risk for skin cancer.[4] Data needed to assess the success of this strategy have not been published. In 2000, there were 271 deaths from skin cancer (2.4/100,000 population), while in 2012 there were 386 (3.4 per 100,000). In both years, it was the $13^{\text {th }}$ most frequent cause of cancer deaths.[10]

Other cancer sites Today, screening tests for cancer at various sites are being evaluated through a range of trials that include so-called advanced technologies. Policymakers in each country must decide whether to include screening innovations in national programs, based on emerging scientific evidence as well as their own epidemiological and economic conditions.

\section{FINAL CONSIDERATIONS}

Through its Comprehensive Cancer Control Program, Cuba, despite its economic limitations, has established a screening strategy that enables use of advanced technology based on current scientific evidence and with a favorable cost-benefit ratio, the latter due to broad use of domestically manufactured products. The general public and health personnel need to be more aware of the strategy, and coverage should be expanded, either through referrals by primary health care teams or as requested by patients at family doctor-and-nurse offices. We also need screening studies conducted in real-world Cuban conditions, studies that look not just at higher detection rates (diagnosis of premalignant lesions or early-stage cancer) but also at the strategy's main goal: reduced mortality. Wh

\section{REFERENCES}

1. World Health Organization. National Cancer Control Programmes. Policies and managerial guidelines [Internet]. 2nd ed. Geneva: World Health Organization; c2008 [cited 2014 Mar 10] 204 p. Available from: http://www.who.int/repro ductivehealth/publications/cancers/92415455 77/en/

2. World Health Organization. Detección temprana. Control del cáncer. Aplicación de los conocimientos. Guía de la OMS para desarrollar programas eficaces [Internet]. Geneva: World Health Organization; 2007 [cited 2014 Mar 10]. 48 p. Available from: http://www.who.int/cancer/publications/can cer_control_planning/es/. Spanish.

3. Fernández JA, Díaz J. Algunas consideraciones teóricas sobre la pesquisa activa Rev. Cubana Med Gen Integr [Internet]. 2009 [cited 2014 Apr 10];25(4):107-16. Available from: http://scielo .sld.cu/pdf/mgi/v25n4/mgi11409.pdf. Spanish.

4. Ministry of Public Health (CU). Programa Integral para Control del Cáncer en Cuba. Estrategia Nacional para el Control del Cáncer. Havana: Ministry of Public Health (CU); 2012 [cited 2014 Mar 10]. 65 p. Available from: http://www .paho.org/cub/index.php\%3Foption\%3Dcom docman $\% 26$ task\%3Ddoc download $\% 26$ gid\%3D378\%26Itemid\%3D\&sa=U\&ei=3d6pU5a 5KlilyASy74GoBA\&ved=0CAYQFjAA\&client=int ernal-uds-cse\&usg=AFQjCNGbj82tkF2Qv8Vdx YtRr-UC5j1XcQ. Spanish.

5. National Cancer Institute (US) [Internet]. Bethesda (US): National Cancer Institute (US); 2014. Exámenes de detección del cáncer del cuello uterino; 2014 [updated 2014 Jun 13; cited 2014 Apr 22]; [about 3 screens]. Available from: www .cancer.gov/espanol/pdq/deteccion/cuelloute srino/HealthProfessional. Spanish.

6. U.S. Preventive Services Task Force [Internet]. Maryland: U.S Preventive Services Task Force; c2014. Screening for Cervical Cancer; 2012 [cited 2014 Apr 22]; [about 1 screen]. Available from: http://www.uspreventiveservicestaskforce .org/uspstf/uspscerv.htm

7. Saslow D, Solomon D, Lawson HW, Killackey M, Kulasingam SL, Cain J, et al. American Cancer Society, American Society for Colposcopy and Cervical Pathology, and American Society for Clinical Pathology screening guidelines for the prevention and early detection of cervical cancer. CA Cancer J Clin [Internet]. 2012 MayJun [cited 2014 Apr 22];62(3):147-72. Available from: http://www.ncbi.nlm.nih.gov/pmc/articles/ PMC3801360/
8. World Health Organization. WHO guidance note: comprehensive cervical cancer prevention and control: a healthier future for girls and women. Switzerland: World Health Organization; 2013 [cited 2014 Apr 22]. 16 p. Available from: http://apps.who.int/iris/bitste am/10665/78128/3/9789241505147_engpdf?ua=1

9. Ministry of Public Health (CU). Programa Diagnóstico Precoz del Cáncer de Cuello del Útero [Internet]. Havana: Ministry of Public Health (CU); 1999 [cited 2014 Apr 21]. 53 p. Available from: http://files.sld.cu/sida/files/2012/01/ prog-detec-canc-cervicout.pdf. Spanish.

10. National Health Statistics and Medical Records Division (CU). Anuario Estadístico de Salud 2012 [Internet]. Havana: Ministry of Public Health (CU); 2013 Apr [cited 2014 Apr 10]. 190 p. Available from: http://files.sld.cu/dne/files/2013/04/ anuario 2012.pdf. Spanish.

11. National Cancer Institute (US). Bethesda (US): National Cancer Institute (US); c2014. Exámenes de detección del cáncer de seno (mama); 2014 [updated 2014 Apr 18; cited 2014 Apr 22]. Available from: www.cancer.gov/espanol/pdq/dete ccion/seno/HealthProfessional. Spanish.

12. U.S. Preventive Services Task Force. Screening for breast cancer: U.S. Preventive Services Task Force recommendations statement. Ann Intern Med. 2009 Nov 17:151(10):716-26.

13. World Gastroenterology Organization; International Digestive Cancer Alliance. Tamizaje del cáncer colorrectal [Internet]. Milwaukee (US): World Gastroenterology Organization; 2007 [cited 2014 Mar 12]. 19 p. Available from: http://www .worldgastroenterology.org/assets/downloads /es/pdf/guidelines/cancer_colorectal_tamiza je_screening_y_vigilancia.pdf. Spanish.

14. American Cancer Society [Internet]. Atlanta: American Cancer Society; c2014. Detailed Guide: Colon and Rectum Cancer; 2012 [cited 2014 Mar 13]. Available from: http://www .cancer.org/Cancer/ColonandRectumCancer/ DetailedGuide/index

15. Aune D, Chan DS, Lau R, Vieira R, Greenwood DC, Kampman E, et al. Dietary fibre, whole grains, and risk of colorectal cancer: systematic review and dose-response meta-analysis of prospective studies. BMJ. 2011 Nov 10;343:d6617.

16. American Cancer Society [Internet]. Atlanta: American Cancer Society; c2014. Recomendaciones de la Sociedad Americana Contra el Cáncer para la detección temprana del cáncer colorrectal; 2014 [cited 2014 Mar 13]. Available from: http://www.cancer.org/espanol/cancer/ colonyrecto/guiadetallada/cancer-colorrectal -early-deteccion-recomendations. Spanish.

17. National Cancer Institute (US) [Internet] Bethesda (US): National Cancer Institute (US); c2014. Exámenes de detección del cáncer colorrectal; 2014 [cited 2014 Apr 22]. Available from: www.cancer.gov/espanol/pdq/dete ccion/colorrectal/HealthProfessional. Spanish.

18. U.S. Preventive Services Task Force [Internet] Maryland: U.S. Preventive Services Task Force; c2014. Screening for Colorectal Cancer: Recommendation Statement; 2008 Oct [cited 2014 Mar 12]. Available from: http://www.uspreventive servicestaskforce.org/uspstf08/colocancer/co lors.htm

19. Herrera RC, Rodríguez R, Vivar JR, Lorenzo A, López L, Gato E, et al. SUMASOHF para el diagnóstico de sangre oculta: evaluación analítica desarrollada en el Centro de Inmunoensayo [Internet]. Paper presented at: CUBA SALUD 2012. Proceedings of the Public Health International Convention CUBA SALUD 2012; 2012 Dec [cited 2014 Apr 23]; Havana, Cuba. Available from: http://www.convencionsalud2012.sld .cu/index.php/convencionsalud/2012/paper/view Paper/1684. Spanish.

20. Schröder FH, Hugosson J, Roobol MJ, Tammela TL, Ciatto S, Nelen V, et al. Screening and prostate-cancer mortality in a randomized European study. N Engl J Med. 2009 Mar 26;360(13):1320-8.

21. National Cancer Institute (US) [Internet]. Bethesda (US): National Cancer Institute (US); c2014. Estudio de Exámenes de Detección de Cáncer de Próstata, Pulmón, Colorrectal y Ovarios (PLCO): preguntas y respuestas; 2014 [cited 2014 Mar 14]. Available from: http://www.cancer .gov/espanol/noticias/plcoscreeningQand ASpanish. Spanish.

22. Eskersberger E, Finkelstein J, Sadri H, Margreiter M, Taneja SS, Lepor H, et al. Screening for Prostate Cancer: A Review of the ERSPC and PCLO Trials. Rev Urol. 2009 Summer;11(3):127-33.

23. National Cancer Institute (US) [Internet]. Bethesda (US): National Cancer Institute (US); c2014. Análisis del antigen prostático específico (PSA); 2012 [cited 2014 Apr 22]. Available from: www.cancer.gov/espanol/hojas-in formativas/deteccion-diagnostico/antigeno -prostatico-especifico. Spanish.

24. Prostate Cancer Early Detection [Internet]. Pennsylvania: National Comprehensive Cancer Network (US); c2014 [cited 2014 Apr 
21]. 35 p. Available from: http://www.tri-kobe .org/nccn/guideline/urological/english/prostate detection.pdf

25. Immunoassay Center (CU). Prospecto UMELISA PSA. Edición No.2 Código UM 2036 [Internet]. Havana: Immunoassay Center (CU); 2010 Sep [cited 2014 Apr 21]. 11 p. Available from: http://www.tecnosuma.com/Informa cion/Inserts\%20(PDF)/UMELISA\%20PSA.pdf. Spanish.

26. U.S. Preventive Services Task Force [Internet]. Maryland: U.S. Preventive Services Task Force; c2014. Screening for Oral Cancer: Recommendation Statement; 2004 [cited 2014 Mar 15]; [about 3 screens]. Available from: http://www.uspreventiveservicestask force.org/uspstf13/oralcan/oralcanfinalrec.htm

27. The Cochrane Library [Internet]. Massachusetts: John Wiley \& Sons. Intervention Review. Screening programmes for the early detection and prevention of oral cancer. Cochrane Database of Systematic Reviews. 2013 Nov 19 [cited 2014 Jun 20];(11). doi: 10.1002/14651858. CD004150.pub4. Available from: http:// onlinelibrary.wiley.com/doi/10.1002/14651858 .CD004150. pub4/abstract;jsessionid=EEC9E40 7FD309514471C4BA5AE1BBE1F.f01t04

28. Ministry of Public Health (CU). Programa de Detección del Cáncer Bucal [Internet]. Havana: Ministry of Public Health (CU); 2001 Oct [cited 2014 Apr 22]. 16 p. Available from: http://files .sld.cu/sida/files/2012/01/prog-detec-cancer -bucal2001.pdf. Spanish.

29. U.S. Preventive Services Task Force [Internet]. Maryland: U.S. Preventive Services Task Force; c2014. Screening for Skin Cancer: Recommendation Statement; 2009 [cited 2014 Mar 15]; [about 1 screen]. Available from: http://www.uspreventiveservicestask force.org/uspstf/uspsskca.htm

\section{THE AUTHOR}

Rebeca S. González Fernández (tsprognac1@cie.sld.cu), family physician with a master's degree in comprehensive women's health. Assistant professor, Medical University of Havana, and national programs coordinator, TecnoSuma International, Immunoassay Center, BioCubaFarma, Havana, Cuba.

Submitted: April 7, 2014

Approved for publication: July 27, 2014

Disclosures: None 